\title{
En el Umbral \\ de la Noche: \\ Dau al Set entre \\ las Vanguardias \\ Históricas y el \\ Arte Nuevo
}

Sol Enjuanes Puyol

Sol Enjuanes Puyol
Doctora en Historia del arte por la Universidad Autónoma de Barcelona. Es profesora de la Universidad Autónoma de Barcelona y de la Universitat Oberta de Catalunya (UOC) y responsable del catálogo razonado de Joan Ponç (www. joanponc.cat). Ha sido becada por la Fundació Pilar i Joan Miró, el Consell Nacional per la Cultura i les Arts (CoNCA) y por la Comisión Interdepartamental de Investigación e Innovación Tecnológica (CIRIT). Sus principales líneas de investigación son el arte catalán del siglo XX y la innovación pedagósica.

Contacto: sol.enjuanes@uab.cat

Recebido em: 04 de abril de 2017

Aceito em: 05 de setembro de 2017 
Palabras clave: Dau al Resumen: Dau al Set es una revista fundada en Barcelona en el año Set; Vanguardia; Revista; 1948. Sus creadores eran un grupo de jóvenes artistas e intelectuales Barcelona; Posguerra que tenían las vanguardias del primer tercio del siglo XX como referente cultural. Este hecho, sumado a las conexiones que la revista estableció con el informalismo, han condicionado que posteriormente haya sido considerada un hito de la vanguardia española. Una interpretación reforzada por el retraso cultural de la España de aquel momento, que vivía bajo el régimen dictatorial del general Franco.

KEywords: Dau al Set; Abstract: Dau al Set is a magazine founded in Barcelona in 1948. Avant-garde; Magazine; Its creators were a group of young artists and intellectuals. The avantBarcelona; Postwar garde movements of the beginning of the twentieth century were their cultural reference. This fact, added to the connections that the magazine established with the art informel, have conditioned that it has been considered a milestone of the Spanish avant-garde. An interpretation reinforced by the cultural backwardness of Spain at that time, ruled by the dictatorial regime of General Franco. 
En el Umbral de la Noche: DaU al Set entre las Vanguardias Históricas y el Arte Nuevo

Vanguardia e innovación son dos conceptos que aparecen íntimamente asociados a la revista Dau al Set. ${ }^{1}$ Sus páginas nos trasladan a universos literarios, plásticos y teóricos que fijan su mirada en el pasado y a la vez revelan ansias de avanzar por nuevos caminos. Plasman la voluntad de revisitar caminos transitados por el dadaísmo y el surrealismo y de restablecer unos vínculos que habían quedado interrumpidos abruptamente por la guerra civil española (1936-1939). Su primer número² vio la luz en 1948, en un ambiente hostil a la experimentación estética, cuando las heridas provocadas por la contienda bélica aún estaban abiertas y eran visibles. España vivía bajo un régimen dictatorial que coartaba todo tipo de libertades, era un "tiempo oscuro", una larga noche poblada por cenizas. ${ }^{3}$

Es en la Barcelona de los años 1940 cuando coinciden los pintores Modest Cuixart, Joan Ponç y Antoni Tàpies, el poeta Joan Brossa, el filósofo Arnau Puig y el editor Joan-Josep Tharrats, ${ }^{4}$ un encuentro que dio pie a Dau al Set. Una revista clandestina que nacía con vocación de ir a contracorriente

1 Dau al Set está parcialmente disponible en: http://mdc2.cbuc.cat/cdm/search/collection/ dauset. Última consulta agosto 2017.

2 En ningún número se incluyó pie de imprenta para dificultar la acción de la censura. Solamente en el primero se hizo constar a Tharrats como fundador y a Ponç como director, unas atribuciones que de hecho tampoco se correspondían con sus funciones reales en la revista.

3 Las metáforas relacionados con la noche y la oscuridad para referirse a los años de la guerra civil y la posguerra han sido muy habituales. A modo de ejemplo, ver: Bozal, Valeriano. "La posguerra. Periodos de un tiempo oscuro". En: Historia de la pintura y la escultura del siglo XX en España. Vol. II, 1940-2010. Madrid: La Balsa de la Medusa, 2013; Foix, J. V. Les irreals omegues. Barcelona: L'Amic de les Arts, 1949; y Brossa, Joan. "Presència forta". En: Algol, [Barcelona, 1946].

4 En 1948 Tharrats todavía no había desarrollado su trayectoria pictórica. 
y de proyectarse hacia un futuro incierto a la vez que buscaba anclajes culturales en el pasado y que optaba por un posicionamiento estético que rehuía el conservadurismo impuesto por los organismos oficiales y las leyes del mercado. ${ }^{5}$ Era una publicación intelectualmente ambiciosa pero de formato y tirada modestos: algunos números constan tan solo de ocho páginas y los 100 ó 150 ejemplares que se podían llegar a editar se distribuían personalmente entre el grupo de conocidos de sus fundadores y colaboradores. A pesar de las dificultades y la escasa repercusión que tuvo en su momento ha acabado convertida en un referente vanguardista. ${ }^{6}$

El nombre en sí mismo era toda una declaración de intenciones. La elección de la lengua catalana, prohibida y perseguida por el gobierno del general Franco, era un desafío que no significaba la exclusión de otros idiomas. El castellano y el francés conviven en sus páginas con una normalidad que en la España de aquel entonces era una anomalía. Por otro lado, Dau al Set —en castellano, dado al siete- invocaba una realidad

5 Llorente Hernández, Ángel. "Artes plásticas y franquismo (1939-1951). En: L'art de la victòria: Belles Artes y franquisme a Catalunya. Barcelona: Columna, 1996, 34. Para un análisis más completo de la situación artística ver: Marzo, Jorge Luis y Mayayo, Patricia. "Del fascismo a la desideologización del arte". En: Arte en España (1939-2015): Ideas, prácticas, políticas. Madrid: Cátedra, 2015. También la exposición Campo cerrado, celebrada en el Centro de Arte Reina Sofía de Madrid, ha puesto de relieve el conservadurismo que imperaba en el ámbito de la cultura durante los primeros ańos de la dictadura franquista y las dificultades de las propuestas vanguardistas para encontrar vías de difusión, ver: Campo cerrado: Arte y poder en la posguerra española. 1939-1953. Madrid: Centro de Arte Reina Sofía, 2016

6 Para conmemorar el cincuenta aniversario de la publicación se celebraron dos exposiciones que pusieron énfasis en esta visión, ver: Dau al Set. El foc s'escampa. Barcelona 1948-1955. Barcelona: Centre d'Art Santa Mònica, 1998 y Dau al Set. Barcelona: Museu d'Art Contemporani de Barcelona, 1999. 
imposible, la séptima cara del dado, un elemento que conecta con el juego y el azar, conceptos que nos remiten al universo creativo del dadaísmo y el surrealismo e incluso al poema de Mallarmé "Une coup de dés jamais n'abolira le hasard" y a La septième face du dé de Georges Hugnet.

Dau al Set no era un fenómeno aislado, se sumaba a iniciativas que apuntaban en la misma dirección: convertirse en altavoz de nuevos creadores y difundir un sustrato cultural que reivindicaban como propio en un momento difícil para la cultura catalana y también para el conocimiento todo aquello que acontecía fuera del territorio español por la imposición de una dictadura autárquica. Primero fue la revista Poesia, fundada por el poeta Josep Palau i Fabre y publicada entre 1944 y 1945 , para dar a conocer la poesía catalana y también autores internacionales, con una especial atención a los autores franceses. Y en 1946 apareció Ariel, que estuvo en activo hasta 1953 con el fin de dar a conocer el panorama literario y artístico catalán e internacional. Incluso podemos mencionar la efímera Algol, un proyecto editorial considerado el embrión de Dau al Set, con la publicación de un solo número a finales de 1946 en el que colaboraron de algunos de los artífices de Dau al Set (Brossa, Ponç y Puig). Una diferencia sintomática entre estas revistas y Dau al Set es que mientras Poesia y Ariel mantuvieron un diseño y una cabecera estables a lo largo de los años, Dau al Set estaba abierta a un nivel de experimentación formal más intenso que dio como resultado cuadernos de apariencia dispar. Por otro lado, también partían de planteamientos ideológicos diferentes, Ariel tenía un claro compromiso patriótico con la cultura catalana y optó por 
el monolingüismo, mientras que en Dau al Set la lengua catalana convivía con aportaciones en otras lenguas y el compromiso más que patriótico era estético. ${ }^{7}$ En cualquier caso, todas ellas compartían la voluntad de suplir un vacío cultural.

Y aún cabría mencionar Cobalto, una revista especializada en arte que apareció en 1947 y que acabó convertida en un referente de la divulgación del arte moderno y en una promotora de relevantes actividades artísticas. ${ }^{8}$ Una publicación con una entidad y ambición muy superiores a las de Dau al Set pero que ayuda a dibujar el panorama en el cual surgió esta modesta publicación impulsada por un grupo de jóvenes inquietos.

Estamos ante una revista irregular tanto en su periodicidad como en su concepción. ${ }^{9}$ Hojearla permite observar los giros de diseño y concepto que sufrió desde la publicación del primer número, en 1948, hasta el último, aparecido en 1956. Una falta de uniformidad que sirvió para suscitar cierta polémica sobre la verdadera cronología de la revista y cuestionar si todos los números publicados podían ser considerados realmente parte de Dau al Set. Brossa llegó a afirmar que solamente lo eran los ejemplares de la revista aparecidos entre 1948 y 1949 y su voz fue abiertamente crítica con ciertos

7 Samsó, Joan. La cultura catalana: entre la clandestinitat i la represa pública. Vol. II. Barcelona: Publicacions de l'Abadia de Montserrat, 1995, 70.

8 Vidal Oliveras, Jaume. "Cobalto, història d'una iniciativaa editorial (1947-1953). En: Locus Amoenus, n. 3, 1997, 215-240.

9 Cabe destacar que ni la periodicidad, ni la extensión de la revista se mantuvieron constantes. Así mismo vale la pena destacar que sus cuadernos no tienen una numeración correlativa, simplemente consignan la fecha de publicación. 
En el Umbral de la Noche: DaU al Set entre las Vanguardias Históricas y el Arte Nuevo

planteamientos de la revista como explicitó en un poema-carta dirigido a Tàpies — que se hallaba en París:

Dau al Set continua essent l'obscura revisteta

representativa només de les nostres minúcies.

En Ponç, en Puig i jo no volem respirar més

en aquest estretall $i$, davant les respostes

seques del director, hem deixat de col.laborar. Ja veuràs,

ja veuràs els números que surten i els propers que sortiran.

Són ben plens de mort, els desventurats. ${ }^{10}$

Era el año $1951^{11}$ cuando Brossa criticaba la línea editorial de Tharrats, a quien atribuía la función de "director", y auguraba la muerte de la revista. Le restaba importancia y minimizaba su trascendencia al cualificarla de "oscura" y al denunciar que tan solo representaba sus "minucias". Una visión que entra en clara contradicción con la actual, con la consideración de Dau al Set como una herramienta fundamental de la recuperación

10 Brossa, Joan. "Antoni Tàpies". En: Ball de sang, Barcelona, Crítica, 1982, 317-318. En el borrador de una carta inédita también dirigida a Tàpies, que se conserva en la Fundación Joan Brossa, el poeta insistía en su crítica a Tharrats: "Per ací tot segueix igual. En Ponç va treballant, jo intensament, com ja pots suposar; en Tharrats continua la carrera descendent del Dau al Set i Dau al sis... Dau al cinc... Dau al quatre... (aquest any, ja obertament, hi col-laborarà tot Cristo)".

11 Ese mismo se celebró una exposición de los miembros de Dau al Set (Sala Caralt, octubre de 1951) que para algunos estudiosos significó el punto final de la revista y atribuyen a Tharrats la continuidad de la cabecera. De todos modos vale la pena aclarar que sus fundadores siguieron colaborando hasta años después a pesar que Puig se trasladó a Madrid, Tàpies a París, Cuixart a Lyon y un poco más tarde, Ponç a São Paulo. Ver: Miralles, Francesc. Història de l'art català. Vol. VIII, L’època de les avantguardes 1917-1970. Barcelona: Edicions 62, 1987, 227; y Vicens, Francesc. "El «Dau al Set»". En: Ética i estètica dels anys 40-50. [Barcelona: Associació de Personal de la Caixa de Pensions per a la Vellesa i d'estalvi, 1973], 21-43. 
de la vanguardia. En realidad, aunque Brossa anunciaba el cese de su colaboración el mes de noviembre de aquel mismo año publicó "Oracle sobre Joan Ponç” y aún realizaría cinco nuevas aportaciones en cuadernos posteriores. De todos modos, el malestar expresado por el poeta y la continuidad de su vinculación con la revista, son indicativos de la falta de alternativas para dar salida a sus creaciones y que a pesar de la falta de entendimiento con Tharrats los dos siguieron vinculados a Dau al Set. Además pone de relieve las tensiones que se vivieron en el seno de la publicación y las dificultades para llegar a acuerdos y gestionar la suma de aportaciones de sus fundadores. ${ }^{12}$

Después de la publicación de dos primeros números marcados por la contención formal y el eclecticismo temático, Dau al Set experimentó un primer cambio que marcaba su transformación en un campo abonado para la experimentación. La cabecera elaborada con una tipografía diseñada exprofeso, ${ }^{13}$ que rehuía las tipos estandarizadas, desapareció definitivamente en el tercer número y el nombre de la publicación se convirtió en un elemento gráfico más de la cubierta diseñada por Ponç en blanco y negro, poblada por seres deformes y enigmáticos rodeados de símbolos y grafismos. Un cuaderno que además contenía dos dibujos de Tàpies, una breve obra de teatro de Brossa titulada "El crim", un artículo de Tharrats y otro de Puig,

12 Coca, Jordi. Joan Brossa o el pedestal són les sabates. Barcelona: Pòrtic, 1971, 56.

13 Según el testimonio de Tàpies, recogido por Imma Julián, el diseño fue obra de Ponç, ver: "Ruptura i renovació en el camp artístic a Catalunya: 1940-1955". En: D’Art, n. 6-7, mayo 1981, 16-35. 
En el Umbral de la Noche: DaU al Set entre las Vanguardias Históricas y el Arte Nuevo

“...Hi ha, també, el ballet” y "Jean-Paul Sartre” respectivamente. Así pues, tan solo entre septiembre y noviembre la revista había experimentado una transformación radical que acabaría por confirmarse en el cuarto número en un texto que anunciaba la entrada de la revista "en un período intenso y más nutrido". ${ }^{14}$ Una intensidad que quedó plasmada de forma extraordinaria en el número de enero-febrero de 1949, realizado íntegramente por Ponç y Brossa, donde la experimentación plástica y literaria conviven y dialogan en unas páginas que destilan unas ansías de experimentación inéditas. ${ }^{15}$ Textos e imágenes comparten página y dan forma a un cuaderno donde impera el componente visual: las palabras entran en juego con los dibujos y adquieren un explícito protagonismo gráfico. Algunas de ellas carecen de significado ("Brinquis", "Uou”, "Ne tavai") mientras otras forman frases enigmáticas (I patarrau diu: /"En una cova fosca les berrugues / fan un fil vermell'). Los dibujos recrean figuras raras, algunas con resonancias humanas, son formas que renuncian al naturalismo para trasladar al lector a un espacio imaginario, al universo creativo de sus autores. No se trata de una suma de colaboraciones, ni de una sucesión de grafías y dibujos, sino de una creación con una doble dimensión: la plástica y la literaria, que conviven en un plano de igualdad. ${ }^{16}$ Esta línea de trabajo se mantuvo

14 "Al sud de l'hivern", Dau al Set, diciembre 1948, [p. 2].

15 Ponç y Brossa colaboraron muy estrechamente en dos números de Dau al Set, el mencionado de enero-febrero de 1949 y en el de abril de 1950. Sobre la relación entre estos dos creadores ver: Bordons, Glòria. "Fer reviure unes flamarades exemplars". En: Brossa, Joan. Carrer de Joan Ponç. Barcelona: Edicions Poncianes, 2010, 13-54.

16 Se conserva la maqueta de un número que quedó inédito también elaborado por Ponç y Brossa elaborado bajo las mismas premisas que el citado. 
en los números siguientes a pesar que el grado de complicidad alcanzado por Ponç y Brossa sea difícil de reencontrar: Cuixart y Tàpies elaboraron conjuntamente un número que incorporaba un texto de Enrique de Villena manuscrito; Tharrats realizó un cuaderno en homenaje a Georges Méliès donde el uso del collage convertía cada ejemplar en único; y el poeta Juan-Eduardo Cirlot y Cuixart colaboraron en un número más modesto, cuatro páginas con la portada y un colofón realizados por Cuixart, pero de especial significación porque marcó el inicio las contribuciones de este poeta en la revista.

A partir del número elaborado por Ponç y Brossa, la revista abandonó la rigidez de un formato estandarizado para dar un mayor protagonismo a la creatividad. Se iniciaba una nueva manera de entender y crear Dau al Set que se mantuvo con altibajos pero que marcó un punto de inflexión en su evolución porque posibilitó creaciones insólitas que ponían un especial acento en el componente visual de la publicación. Hizo posible que Dau al Set se situara en la órbita del arte más avanzado y que con el tiempo quedara definitivamente vinculada a la recuperación de la vanguardia.

Hablar de vanguardia artística a inicios de 1949 significaba referirse al informalismo y al expresionismo abstracto, tendencias que exploraban en Europa y Estados Unidos artistas como Dubuffet, Fautrier, Pollock, de Kooning, etc. La imágenes de Dau al Set están todavía lejos de conectar con este campo de experimentación a pesar que Tàpies había iniciado el uso de 
materiales y texturas en algunas de sus obras. En la revista se observa una línea estética que conecta más con los movimientos de vanguardia anteriores a la guerra civil que con las nuevas propuestas surgidas y difundidas, sobre todo, en Francia y en Estados Unidos. Las figuras deformadas y monstruosas, la profusión del collage y la creación de asociaciones extrañas y sorprendentes, así como la recuperación de grabados antiguos y de ciertas imágenes de la cultura popular, nos remiten a la sensibilidad del expresionismo, del dadaísmo y del surrealismo. Así mismo, los textos de Brossa encajaban con recursos expresivos del dadaísmo y el surrealismo, con el gusto por la apropiación y la exploración de los sinsentidos de las palabras, por recrearse en sus formas gráficas y por la creación de universos imaginarios.

Cuando Dau al Set amplía su nómina de colaboradores se producen incorporaciones muy diversas y heterogéneas que confirman el eclecticismo de la revista y su doble mirada, la proyectada hacía los creadores coetáneos y la que se esforzaba en recuperar lazos con referentes culturales que eran denostados por la dictadura franquista. Es precisamente esta doble mirada la que conecta definitivamente esta publicación con la vanguardia porque mientras se ocupa de difundir jóvenes poetas y artistas también reservaba espacio para creadores que habían tenido una relación clara con los movimientos de vanguardia del primer tercio del siglo XX. En este punto es especialmente significativa la presencia del poeta J. V. Foix, una figura clave de la generación que había estado en activo antes de la guerra y atento a los ismos que nacían en la Europa de aquellos años, sintió un gran interés 
por el maquinismo futurista y los recursos creativos del surrealismo. En Dau al Set Foix publicó: "Telegrames" (diciembre 1948), "Balada dels cinc mariners exclusius, i del timoner que era jo"17 (octubre 1950), "Còpia d'una lletra tramesa a na Madrona Puigarnau, de Palau ça Verdera” (diciembre 1951) y “Tot alejava aquella nit..." (junio-julio 1952). Además, la revista además se hizo eco de la aparición de su poemario Les irreals omegues con la publicación de una reseña (mayo 1950).

Foix representaba una generación de intelectuales que había luchado por la difusión y la práctica de unas técnicas creativas avanzadas en una época compleja, marcada por los vaivenes políticos, pero que no arrastraba el lastre de una guerra fratricida. Con la imposición de la dictadura su proyección intelectual quedó en suspenso momentáneamente pero en breve se convirtió en una figura clave para una joven generación que consideraban que la creación era experimentación. En un momento de acusado aislamiento cultural y económico, Foix representaba un sustrato cultural vanguardista accesible para los creadores de Dau al Set. Él y también su biblioteca ayudaron a forjar la personalidad creativa de los miembros de la revista, de los artistas plásticos pero en especial la de Brossa, quien reconoció el papel de este poeta en su formación. ${ }^{18}$

En esta línea hay que situar también la colaboración de Sebastià Gasch un crítico de arte alineado con la vanguardia de los años 1920 y acérrimo defensor de Miró desde los inicios de su trayectoria que había firmado un

17

18 Coca, Jordi. Joan Brossa o el pedestal són les sabates. Barcelona: Editorial Pòrtic, 1971, 28. 
En el Umbral de la Noche: DaU al Set entre las Vanguardias Históricas y el Arte Nuevo

demoledor manifiesto artístico en 1928. ${ }^{19}$ En Dau al Set publicó "Elogi de la deformació”, ${ }^{20}$ un alegato en favor del arte que evitaba la imitación naturalista y que apostaba por la deformación como herramienta para conseguir una mayor expresividad. Un recurso presente en numerosas culturas: desde la egipcia, pasando por la asiática y la africana, hasta llegar a la pintura románica y el Greco. Así mismo vale la pena destacar la reproducción de dos dibujos de Dalí, uno para encabezar los "Telegrames" de Foix (diciembre 1948) y otros para ilustrar la portada de un artículo del historiador y crítico de arte Juan Antonio Gaya Nuño, "Medio siglo de movimientos de vanguardia en nuestra pintura" (diciembre 1950). Para completar la conexión de Dau al Set con las figuras más relevantes de la vanguardia afincada en Cataluña tan solo falta Miró, ${ }^{21}$ a quien Brossa dedicó un artículo ilustrado con un pequeño dibujo del artista (mayo 1949).

Estas colaboraciones delatan el interés por el sustrato cultural de los años 1920 . Foix, había contribuido a la difusión de las vanguardias a través de revistas como L'Amic de les Art y en su poesía aunaba vanguardia y

19 El Manifest groc denunciaba la cultura catalana más conservadora y apostaba por un arte nuevo, reivindicaba una modernidad que incluía el deporte, la aviación, el jazz, la fotografía, etc. y ensalzaba una lista de creadores ente los cuales destacamos a Picasso, Gris, Miró, Le Corbusier, Tzara, Elouard, Cocteau, García Lorca, Strawinsky y Breton. Además de Gasch el manifiesto estaba firmado por Dalí y Lluís Montanyà.

20 Dau al Set, julio-septiembre, 1949.

21 Enjuanes Puyol, Sol. "Reflexiones entorno a la visita de Dau al Set a Joan Miró". En: Dau al Set: Joan Brossa, Juan Eduardo Cirlot, Modest Cuixart, Joan Ponç, Arnau Puig, Antoni Tàpies, Joan Josep Tharrats. Barcelona: Fundación Fran Daurel, 2009, 89-95. 
tradición, incorporaba la experimentación formal de los ismos europeos a la vez que reseguía las raíces de la lengua catalana. Gasch era un crítico atento a los avatares artísticos de Miró pero también a la cultura entendida con un sentido suficientemente amplio para incluir no solo la denominada alta cultura sino también las artes circenses y el mundo del espectáculo. Unas presencias que sumadas a las puntuales de Dalí y Miró dibujan unas líneas de filiación que enlazan con creadores e intelectuales que estuvieron en activo antes del obligado y trágico paréntesis de la guerra civil. En realidad, a través de Dau al Set asistimos a la construcción de la identidad artística de sus fundadores, de su esfuerzo por enlazar con una tradición que había quedado en suspenso y que se caracterizaba por sus contactos con las vanguardias internacionales.

Los jóvenes artistas que habían fundado Dau al Set estaban en el inicio de su trayectoria, de hecho su lenguaje plástico evolucionó en paralelo a la revista. El proceso de experimentación plástica de Cuixart, Ponç y Tàpies, iniciado bajo el influjo de los recursos expresivos explorados en el expresionismo, el cubismo y el surrealismo, determinó personalidades artísticas propias y caminos diferentes. También Brossa siguió su búsqueda transitando por formas poéticas tradicionales, como el soneto, hasta llegar a la apropiación de frases extraídas de contextos cotidianos y a los juegos gráficos con las grafías. Para todos ellos, Dau al Set fue un acicate creativo pero no una ocupación principal: Cuixart participó en diez números, Ponç en trece, Tàpies en once y Brossa en dieciocho, de los más de cincuenta que 
En el Umbral de la Noche: DaU al Set entre las Vanguardias Históricas y el Arte Nuevo

se llegaron a publicar. ${ }^{22}$ Sus colaboraciones se concentran en los primeros años de vida de la revista, entre 1948 y 1951, y a partir de este año fueron esporádicas y más cuando en 1953 dio un importante giro: los cuadernos se convirtieron en monográficos temáticos más voluminosos, con una trabajo de edición más profesional, se pasó a publicar trimestralmente y en ocasiones se contó con el patrocinio de algunos mecenas. En 1956 salió a la luz el último número con un texto de Michel Tapié, el crítico de arte que en el número anterior ya había publicado un ensayo sobre Tàpies. ${ }^{23}$ Dos cuadernos que reafirman el cambio de dirección que habían tomado las artes plásticas en los años 1950 con la aparición del informalismo en Europa y el expresionismo abstracto en Estados Unidos. Tapié había acuñado el término art autre para referirse a un arte basado en el gesto y la improvisación, una tendencia que rompía los conceptos tradicionales de composición y que relacionaba con el término informe, sin forma, que derivaría en informal y se consolidaría como término para definir una tendencia artística.

22 Incluimos el texto "Al sud de l'hivern" (Dau al Set, diciembre 1948), que aparece sin firmar pero razonablemente atribuido a Brossa, ver: Granell, Enric. "Dau al Set, una conjunción de volcanes desconocidos". En: Dau al Set: Joan Brossa, Juan Eduardo Cirlot, Modest Cuixart, Joan Ponç, Arnau Puig, Antoni Tàpies, Joan Josep Tharrats. Barcelona: Fundación Fran Daurel, 2009, 72. También el número extraordinario diseñado por Enric Tormo (Dau al Set, diciembre 1949) aunque este cuaderno no siempre se consiera parte integrante de la colección, ver: "Sumari de la revista Dau al Set", Dau al Set. Barcelona: Museu d'Art Contemporani de Barcelona, 1999, 150.

23 "Antoni Tàpies et l'oeuvre complète". En: Dau al Set, 1955 ; y "Esthétique en devenir". En: Dau al Set, 1956. 
Los insólitos textos de Brossa y las aportaciones plásticas de Cuixart, Ponç y Tàpies apuntaban hacía las vanguardias del pasado con la idea de construir un arte "nuevo", un concepto que en aquella época se prefería al de vanguardia. Las páginas de Dau al Set constatan el camino seguido por la revista pero también de sus creadores, que tenían la clara voluntad de alejarse de la estética imperante, de los kilómetros de aburrida pintura de paisaje y de retratos que llenaban las salas de exposiciones, de las obras concebidas como una muestra de habilidad más que de creatividad. ${ }^{24}$ En el punto inicial de la trayectoria se acercaron a los logros de las vanguardias del primer tercio del siglo XX para aproximarse finalmente al informalismo, una corriente estética que había marcado la recuperación del arte de vanguardia en Europa después de la segunda guerra mundial.

Sin lugar a dudas Dau al Set tejió conexiones con la vanguardia pero aún así cabe preguntarse sobre si fue realmente una revista vanguardista puesto que dichas relaciones son extemporáneas. Por ejemplo, los ensayos de Tapié se publican a mediados de la década de 1950, cuando el arte informal hace una década que se desarrolla en Francia. La respuesta la dio el escritor José Marín-Medina: ${ }^{25}$

La verdad es que Dau al Set considerado en sí mismo supondría un hecho cultural de poco alcance, un lance juvenil basado en la amistad y la concurrencia de ciertos ideales de seis artistas y escritores que celebraron

24 Gaya Nuño, Antonio. "Medio siglo de movimientos vanguardistas en nuestra pintura". Dau al Set, diciembre 1950.

25 Marín Medina, José. “Dau al Set: contexto y plenitud”. En: Cuadernos Guadalimar, n. 7 [1978], 35. 
En el Umbral de la Noche: DaU al Set entre las Vanguardias Históricas y el Arte Nuevo

algunas convivencias, exposiciones y representaciones, y que se expresaron colectivamente a través de una pequeńa revista de tirada y repercusión mínimas. Pero igualmente es cierto que si comprendemos aquella práctica artística en el contexto temporal y cultural en que y frente al que se produjo, Dau al Set cobra entonces otras y sobresalientes dimensiones. (Martín-Medina, 1978, 35)

Esta visión puede chocar con la visión actual que da por hecho el carácter avanzado de Dau al Set hasta considerarla un emblema de la recuperación de la vanguardia. ${ }^{26}$ De hecho, el crítico literario Enric Bou, ${ }^{27}$ la ha definido como una revista plenamente vanguardista por su aproximación al surrealismo, tanto en el ámbito literario como artístico.

A pesar de no poder ser considerada un gran logro de la vanguardia por sus características intrínsecas, Dau al Set adquiere una relevancia sobresaliente por la precariedad del contexto cultural en el que surgió. Su excepcionalidad es consecuencia del entorno pero cabe añadir su función como vía de investigación y de encuentro de los creadores más inquietos de la Barcelona de la posguerra. En el momento de la publicación del primer número, los artífices de Dau al Set eran unos jóvenes de apenas veinte años que se hallaban en el inicio de su camino. ${ }^{28}$ Efectivamente fue una aventura de juventud que trascendió el ámbito individual y ha acabado convertida en

26 Dau al Set: La segona avantguarda catalana. Barcelona: Fundació Lluís Carulla, 2011.

27 Bou, Enric. "Temps de resistència. Gèneres i autors". En: Panorama crític de la literatura catalana. Vol. VI, Segle XX: De la postguerra a l'actualitat. Barcelona: Vicens Vives, 2009, 99.

28 Brossa (1919-1998), Cuixart (1925-2007), Ponç (1927-1984), Puig (1926), Tàpies (19232012) y Tharrats (1918-2001). 
un hito cultural. Dau al Set fue un espacio intelectual donde los creadores e intelectuales pudieron compartir sus afanes creativos y poner de manifiesto su ansiedad de influencias.

\section{REEERENCIAS BiBLIOGRÁFICAS}

Bordons, Glòria. "Fer reviure unes flamarades exemplars". En: Brossa, Joan. Carrer de Joan Ponç. Barcelona: Edicions Poncianes, 2010, 13-54.

Bou, Enric. «Temps de resistència. Gèneres i autors». En: Panorama crític de la literatura catalana. Vol. VI, Segle XX: De la postguerra a l'actualitat. Barcelona: Vicens Vives, 2009. 98-146.

Bozal, Valeriano. Historia de la pintura y de la escultura del siglo XX en España. Vol. II, 1940-2010. Madrid: La Balsa de la Medusa, 2013.

Brossa, Joan. Ball de sang, Barcelona, Crítica, 1982.

Brossa, Joan. "Presència forta". En: Algol, [Barcelona, 1946].

[Brossa, Joan]. “Al sud de l'hivern”. En Dau al Set, diciembre 1948, [2].

Campo cerrado: Arte y poder en la posguerra española. 1939-1953. Madrid: Centro de Arte Reina Sofía, 2016.

Coca, Jordi. Joan Brossa o el pedestal són les sabates. Barcelona: Pòrtic, 1971.

Dau al Set, 1948-1956.

Dau al Set. Barcelona: Museu d'Art Contemporani de Barcelona, 1999.

Dau al Set. El foc s'escampa. Barcelona 1948-1955. Barcelona: Centre d'Art Santa Mònica, 1998.

Dau al Set: La segona avantguarda catalana. Barcelona: Fundació Lluís Carulla, 2011.

Enjuanes Puyol, Sol. "Reflexiones entorno a la visita de Dau al Set a Joan Miró". En: Dau al Set: Joan Brossa, Juan Eduardo Cirlot, Modest Cuixart, Joan Ponç, 
En el Umbral de la Noche: DaU al Set entre las Vanguardias Históricas y el Arte Nuevo

Arnau Puig, Antoni Tàpies, Joan Josep Tharrats. Barcelona: Fundación Fran Daurel, 2009, 89-95.

Foix, J. V. Les irreals omegues. Barcelona: L'Amic de les Arts, 1949.

Granell, Enric. "Dau al Set, una conjunción de volcanes desconocidos”. En: Dau al Set: Joan Brossa, Juan Eduardo Cirlot, Modest Cuixart, Joan Ponç, Arnau Puig, Antoni Tàpies, Joan Josep Tharrats. Barcelona: Fundación Fran Daurel, 2009, 71-79.

Julián, Imma. "Ruptura i renovació en el camp artístic a Catalunya: 1940-1955". En: D’Art, n. 6-7, mayo 1981, 16-35.

Llorente Hernández, Ángel. "Artes plásticas y franquismo (1939-1951). En: L’art de la victòria: Belles Artes y franquisme a Catalunya. Barcelona: Columna, 1996, 31-44.

Marín Medina, José. “Dau al Set: contexto y plenitud”. En: Cuadernos Guadalimar, n. 7 [1978], 35-41.

Marzo, Jorge Luis y Mayayo, Patricia. "Del fascismo a la desideologización del arte”. En: Arte en España (1939-2015): Ideas, prácticas, politicas. Madrid: Cátedra, 2015, 19-146.

Miralles, Francesc. Història de l'art català. Vol. VIII, Lèpoca de les avantguardes 1917-1970. Barcelona: Edicions 62, 1987.

Samsó, Joan. La cultura catalana: entre la clandestinitat i la represa pública. vol. II. Barcelona: Publicacions de l'Abadia de Montserrat, 1995.

Vicens, Francesc. "El «Dau al Set»". En: Ética i estètica dels anys 40-50. [Barcelona: Associació de Personal de la Caixa de Pensions per a la Vellesa i d'estalvi, 1973], 21-43.

Vidal Oliveras, Jaume. "Cobalto, història d'una iniciativaa editorial (1947-1953). En: Locus Amoenus, n. 3, 1997, 215-240. 


\section{ILUSTRACIONES}

Dau al Set (enero-febrero 1949) realizado por Joan Ponç y Joan Brossa, portada y página interior
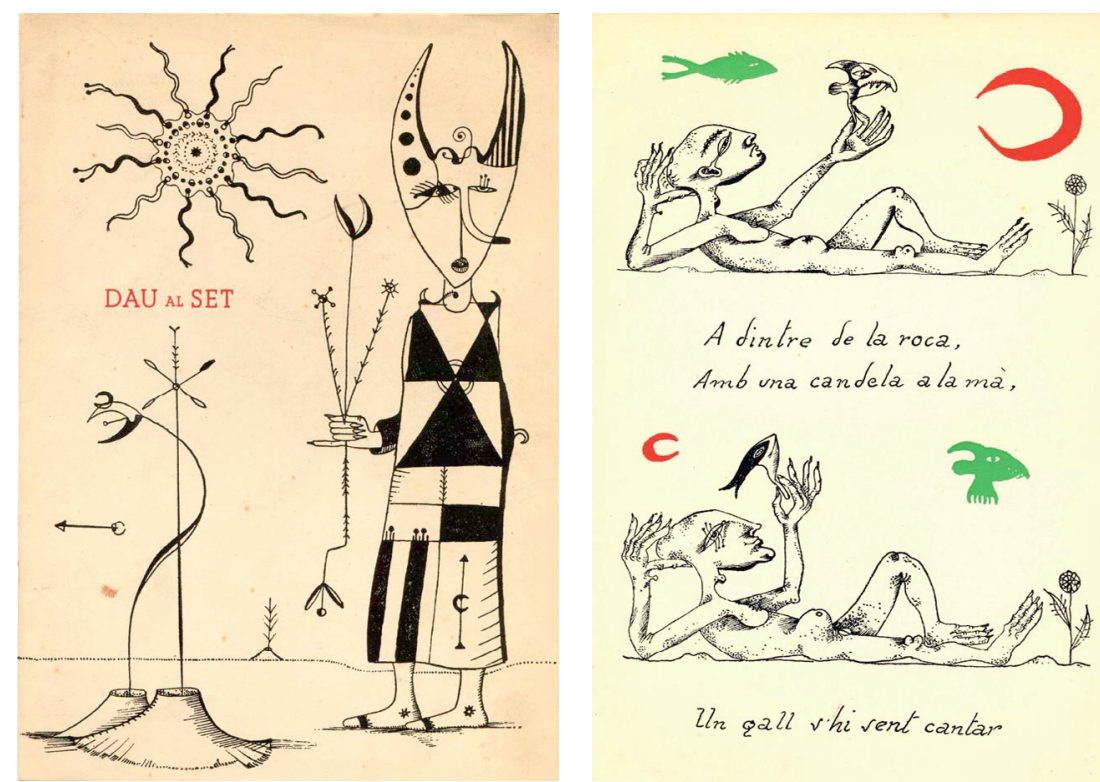

A dintre de la roca.

Amb́ una candela a la má.

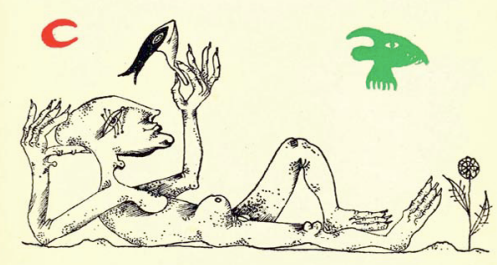

Iln gall vhi vent cantar 